\title{
Stakeholders Management in the Collection and Commercialization of Brown Macroalgae in the District of Marcona, Nazca, Peru
}

\author{
Julie Contreras ${ }^{1}$, Pilar Canales Solis ${ }^{2}$, Dr. Marta Tostes ${ }^{3}$
}

\begin{abstract}
The Peruvian biodiversity management requires that stakeholders are linked to take advantage of commercial opportunities fulfilling with regulations that facilitate their sustainability. Worldwide, the brown macroalgae commercialization is evolving satisfactorily, which is reflected in the increase of its exports. In Peru, the brown macroalgae activity has a social and cultural importance, as it is done by artisanal fishermen and their families, who depend totally or partially on these resources. However, the increase in demand has had a strong impact on the marine biomass which generated continuous concern of local authorities, sector entities and other stakeholders. Therefore, we are looking to integrate initiatives among stakeholders to generate governance. This article analyzes the linkages networks between the previously mentioned actors and concludes that the average link density level is $37.89 \%$. The main actors that can mediate to strengthen these links are the Peruvian Sea Institute and the Ministry of Production, in a joint effort with the local governments and the environmental police. The latter would allow the use of this important resource with a sustainable development framework.
\end{abstract}

Keywords: Brown Macroalgae, Biocommerce, Artisan Fishermen, sustainable governance, sustainable development

\section{Introduction}

The Millennium Development Goals sought to be reflected in national and local planning where there is increasing concern for the governance of natural resources. From the green growth perspective (OECD, 2018), it is important to make productivity improvements using resources in a sustainable manner so that the biodiversity source associated to trade of biodiversity-based products (biotrade) does not have an expiration date. Thus, it is necessary to find equilibrium between socioeconomic development and the growth limits care of resources, taking into account the technological, environmental and social sustainability of those who directly or indirectly integrate the productive chain. For this purpose, it is necessary to generate governability among stakeholders with the framework of formal and informal rules that derive from their relations. These should enable strengthening the sustainable development perspective of an economic activity based on biodiversity.

The commercial activity of brown macoralgae has a great relevance in Peru because it is carried out mainly by artisan fishermen who depend totally or partially on these resources. Besides, brown macroalgae are ecologically important because they are the

\footnotetext{
$\mid{ }^{1}$ Research Assistant, Pontificia Universidad Católica del Perú (PUCP), Perú.

| 2 Research consultant in Ministerio de Desarrollo e Inclusión Social (Development and Social Inclusion Ministry), Perú.

| 3 Main Professor at Pontificia Universidad Católica del Perú (PUCP) in the Management Science Academic Department
} 
basis of the marine ecosystem and they act in different roles (food, larval environment or habitat). They maintain biodiversity to shelter different species that have economic, social and environmental importance within Peruvian artisan fish farming.

In this framework, the research responds to the need to identify all the stakeholders involved in the collection and commercialization of brown macroalgae in Marcona district during the period 2010-2013 and to analyze their relationships and their roles in the economic activity. This could improve the activity management in the area. Besides, the analysis of the existing networks within the chain would allow the development of an efficient social and environmental management, facilitating its governance.

The structure of the article includes in first place the theoretical framework of the research and the context in which it is developed. Then, the applied methodology is presented. Following, an important part is dedicated to the results obtained with the UCINET program. Finally, the research conclusions are mentioned and new stages for the use of the methodology are recommended to guarantee the sustainability of this economic activity.

\section{Literature Review}

The research presents three macro issues that back up the work done. The first one deals with social and environmental management and its relation with governance and governability. In this aspect, the Reform Project of the Mineral Resources Sector of Peru (PERCAN, 2011) defines social management as the set of actions oriented to the creation of social interaction spaces where the involved stakeholders can define activities and make decisions to attend needs and solve social problems. On the other hand, environmental management focuses on the process oriented to manage, plan, evaluate and monitor as efficiently as possible the existing environmental resources in a specific territory, with the purpose of improving the life quality of its inhabitants (Andia Valencia \& Andia Chavez, 2009). These two types of management are related to governance and governability because they are linked to the field of public policies evaluation, that is, institutions, mechanisms and methods. This will condition decision making on the regulation of economic activities, which implies coexistence and cooperation, but also the possible emergence of conflicts (Revesz, 2009). The development of communities, based on some productive activity with the use of natural resources, must visualize their regulation framework. The purpose is to position them in a field of relationships that allows for an adequate economic development by fostering the sustainability of the resources upon which they depend.

The second macro issue is based on the characterization of stakeholders in the productive chains. This characterization starts with their identification and the analysis of stakeholders' map that is directly linked to the social networks theory (Aguirre, 2011). This is because it is a structural type tool that allows access to the variety of existing social relationships that seeks to know the actions and the objectives of their participation. In this field, it is required to highlight the identification of roles and power of the most relevant stakeholders. The stakeholders' map must explore beyond a superficial outlook of the roles; it needs to be understood within a productive chain as a set of economic agents interrelated by market, from input provision to the final 
consumer (Direccion General de Promocion Agraria, 2013). The different stakeholders that participate in the productive chain develop activities making use of their relationships to add value to the product with the purpose of reaching the consumer. This introduces them into a sustainable economic development. Some stakeholders are directly involved in the process and others are dedicated to provide services. They are subject to the influence of their environment, represented by various elements such as for example, the game rules generated from the relationships between stakeholders and the regulation framework in which the activity develops.

The last macro issue links biodiversity, biotechnology and biotrade in productive development. Biodiversity includes the assortment of living beings and groupings found in our planet. It is fundamental, because a great variety of goods and services essential for survival of human beings are obtained from it (Ugalde Gómez, y otros, 2009). Modern biotechnologies are quickly moving from the research stage to the commercial production stage, breaking new ground for green growth in different fields, from the manufacturing sector to medical care and decontamination (The Regency corporation Limited in Asociation with the United Nations, 1998). Biotechnological products and processes are part of our daily life as they offer employment and investment opportunities (Malajovich, 2005, pág. 27). Following this logic, biotrade constitutes a system of economic agents that make use of biodiversity resources but with a sustainable management of biological diversity. This way, the equitable distribution of the benefits derived from the use of biological diversity can be applied supporting socio economic sustainability (of management, production and markets) (Fairlie Reinoso, 2010). This is the basis to comply with national and international legislation and international agreements, respecting the rights of the involved stakeholders, making use and facilitating the access to natural resources and traditional knowledge that enables them to be economically and environmentally sustainable.

\section{Context}

Commercialization of brown macroalgae in the world has evolved satisfactorily in the last years and also exports have considerably increased mainly because the uses given to this resource are varied. Algae contain a high level of alginate which is an important additive for use in food, pharmacological, agricultural and cosmetology industries, among others.

In Peru, the brown macroalgae activity has social importance in the collection, drying, storing and chopping, because it is carried out by artisan fishermen and their families, who depend completely or partially on the resource (Vásquez \& Westermeier 1993). On the other hand, algae are ecologically essential in Peruvian marine ecosystems, not only because they are the basis of benthic trophic chains, but also because they are the natural habitat and refuge of larval settlement and recruitment of young fish (Vásquez \& Santelices 1984, Vásquez 1992, Edding et al. 1994, Vásquez et al. 2001a, 2001b, 2005). In shallow intertidal and subtidal areas the macrocystis and lessonia algae act as engineers of these coastal ecosystems (sensu Jones etal. 1994), housing other species of economic and social importance (e.g. limpets, "loco", hedgehogs, rock fish) (Instituto del Mar Peruano - IMARPE, 2009). 
Marcona is a district where people perform this activity which is representative of the area. This is verified in the records of year 2013 from the Regional Production Bureau of Ica (DIREPRO Ica). According to this record there are 670 formalized artisan fishermen, of whom 126 work exclusively as collectors in the fishing activity. The increase in the exploitation of the resource added to its impact on Marcona district have generated a great concern in local authorities, sector entities and other stakeholders involved. They have perceived the start of an activity without regulation or fishery management plans. This is mainly due to the existence of a great demand in the international market, but also to the need to know and generate regulations that allow for the sustainable development of the activity.

\section{Methodology}

The work methodology of the research enabled the collection and analysis of relevant information for a better understanding of the existing relationship between direct and indirect stakeholders of the productive chain of brown microalgae in Marcona district. Initially, secondary documents were reviewed, compiling and classifying the relevant information that could define the productive chain of the brown macroalgae activity. Later on, the macro-variables that could effectively guide the research were specified. This was very important because it originated the formulation of better questions that gave way to determining and building an adequate criterion regarding the research matter. These macro variables were: legal regulations, environmental management, associative model, list of stakeholders, conflicts, innovation initiatives, techniques in the productive chain, social responsibility, strategic alliances, industrialization initiatives and competitiveness. According to these specific subtopics in the research, classification was made and direct and indirect stakeholders from the productive chain were identified. Stakeholders constantly related to the activity were specified as they were in the best position to answer the previously defined questions.

The interviews and surveys were formulated with these three obtained results: macro variables, stakeholders and questions by subtopics. They were prepared according to each identified stakeholder with the purpose of establishing relationships that would show the reality of the studied context. To do this, first hand information was required from the involved stakeholders, but only seven interviews with the most visible actors were carried out. With them, it was possible to obtain relevant information that enabled consolidation of that previously obtained and to broaden the wide range questions by making possible to gather the information acquired during the initial approaches.

From the seven nterviews to the mentioned stakeholders, a matrix for information collection by stakeholder was prepared. In it, the contexts in which the productive chain is carried out were divided: collection and commercialization and, in turn, they were determined by the macro variables of the research. These can transform the subtopics into questions that enabled to gather information not only from the work they do as part of the chain, but also from the opinions about the relationships generated within it.

The sample selection method was "snowball" by saturation and together with the tools used in this first part, stakeholders' identification was possible. Also the information regarding the productive chain of the activity was deepened and consolidated with a 
greater analysis of the relationships between stakeholders and how these relationships have made and can make possible to improve the development of the activity within Marcona district. To carry out the analysis of the relationships between the involved ones, the Survey of Degree of Relation between Stakeholders was elaborated. The following information was obtained: perception of each stakeholder on its role, evaluation of the role performed by other stakeholders, relationship and work level within the macroalgae activity, and the identification of those that have a relevant position within the productive chain.

Information systematization was done with the use of the UCINET tool which enables the graphical evaluation of how the interrelations work between direct and indirect stakeholders within the productive chain. It analyses the existing links between the stakeholders that influence the regulation framework of the activity and the other stakeholders that participate, with the purpose of visualizing the influence they have on the activity governability. In this aspect the program facilitated the social networks analysis visualizing these interactions on the basis of qualitative type data rather than quantitative (Velázquez Alvarez \& Aguilar Gallegos, 2005).

\section{Findings}

Initially, secondary documentation was reviewed to learn about macroalgae collection and commercialization activity. This helped the identification of a first group of stakeholders directly related with the activity. They were subjected to an unstructured interview that gave as product the identification of more stakeholders within the productive chain. Following, a snowball sampling was used to continue deepening the search for stakeholders and twenty (20) were identified and grouped in four (4) categories: public, private, civil society organizations (OSC) and passive organizations. The most enriching result was to find their purpose in the sustainability of the activity.

Among stakeholders of the OSC group, there are: Marcona Artisan Fishing Community (COPMAR), which aligns the interests of all its members and keeps an organized communication with other stakeholders; Formal Associations, which prioritize their economy and the improvement of their life quality; and Associations to Formalize, which focus on developing their economy. Among the actors of the Public Group were: Sea Institute of Peru - Lima (IMARPE Lima) which carries out research works to balance the fishing activity with biodiversity sustainability; DIREPRO Ica, which promotes extractive and productive activity taking into account the sustainability of resources; IMARPE Marcona, which has good relationships with stakeholders to carry out several research projects; Regional Government, which contributes to the integral and sustainable development of the region; National Service of Natural Protected Areas (SERNANP), which develops projects that safeguard protected natural areas; Marcona Municipality, which deploys projects to promote the fishing activity for a better use of resources; National Superintendence of Customs and Administration (SUNAT), which controls and oversees merchandize traffic; Technological Fishing Institute of Peru (ITP), which proposes the best use of resources in order to generate greater added value to products; Production Ministry (PRODUCE), which promotes improvement of regulations and requirements that frame extractive activities; and Prosecutors for Crime Prevention 
Specialized in Environmental Matters, which investigates and presents complaints whenever corresponds. Among stakeholders of the Private Group, the following were identified: Collectors, which are responsible for collection and transportation of macroalgae; Processing Companies, that carry out algae transformation process (chopping and drying fresh algae) for export; and Export Companies, that commercialize and export the product through brokers abroad. Finally, stakeholders of the Passive Group are: Ecological Police, which protects wildlife flora and fauna of Marcona; Captaincy, which are responsible for regulating and ensuring human life safety, protection of environment and natural resources at the sea; and the Toll Company which ensures care and renewal of transit routes in the area.

Once the stakeholders involved in the activity were identified, an analysis of linkage between them was performed. This analysis was done with the use of two tools previously mentioned: the first was the use of the information collection matrix by stakeholder which allowed the definition and/or establishment of existing links between stakeholders, giving as result a Stakeholders' Linkage Matrix. The second was the use of the social analysis program UCINET, which presents the results considering five (5) indicators: density that shows as percentage the high or low connectivity of the network; centrality that represents the number of stakeholders to which a stakeholder is directly linked; centralization which constitutes a special condition in which a stakeholder exerts a clearly central role being highly connected in the network; intermediation which is linked to the possibility that a stakeholder has to mediate communications between stakeholder peers, also known as bridge stakeholders; and finally, closeness regarding the stakeholder's capacity to reach all stakeholders in the network.

With regard to the centrality indicator, the stakeholders with greater degree of centrality were found to be PRODUCE; COPMAR; IMARPE Marcona and DIREPRO Ica because they topped the first seven positions on the list, together with SERNANP and the processing companies. These data also show that five out of the top seven stakeholders belong to public organizations, which reveals that public organizations are stakeholders that are linked at a higher level with other stakeholders within the activity. On the other hand, it is important to mention that almost all public organizations that are included in these seven stakeholders have governability level 2, which implies that the regulatory framework is present due to these organizations, thus the governability of the activity has high probabilities of strengthening. It was also found that the relationship between those stakeholders has 144 links of the 380 possible and that the maximum number of links is 14, issued by a public organization (PRODUCE).

\begin{tabular}{|c|c|c|c|c|c|}
\hline & & artuent & Inotere & naviones & nonisont \\
\hline & nowa & 14. 2000 & 13.000 & 73.64 & 43.159 \\
\hline & anpente: & ad. ene & 9.00 & n.cos & D. 36 \\
\hline$\therefore$ & & 12. 1200 & 8. & 65.188 & 42.295 \\
\hline & 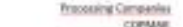 & ${ }_{12}^{12}=000$ & $\begin{array}{l}12.000 \\
11.00\end{array}$ & $\begin{array}{l}69.138 \\
0.15\end{array}$ & 51.158 \\
\hline & cinves & & & 3,10 & $\begin{array}{l}50.205 \\
60.612\end{array}$ \\
\hline 8 & neret veros & 11.6ee & $\begin{array}{l}110,000 \\
11.000\end{array}$ & 157.803 & $57,6,19$ \\
\hline 3 & 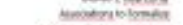 & 12.6e & $\begin{array}{ll}10.600 \\
100\end{array}$ & $\begin{array}{l}32.628 \\
32.62\end{array}$ & 32.612 \\
\hline$z$ & 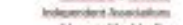 & 30. 060 & 11. & $\$ 2.692$ & S.2.35 \\
\hline & Mrrestantitatex & $\sin _{1000}$ & 8,000 & 42.195 & 42.105 \\
\hline${ }_{7}^{14}$ & 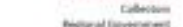 & $7-\infty$ & 9.000 & 3.842 & 47.38 \\
\hline & - & $+\infty$ & 6 & $\lim _{n \rightarrow \infty}$ & $\begin{array}{l}0.369 \\
31.529\end{array}$ \\
\hline in & xis & 9 , nee & 8.000 & 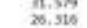 & 盀, \\
\hline 20 & Suncorent & 1.000 & 3.000 & 15.7n & 15.7n \\
\hline 16 & tericonsuns & 2.06 & i, we & 19.686 & t5.2m \\
\hline & carvesy & 1000 & 3.000 & 3. 35 & 15.73 \\
\hline${ }_{13}^{10}$ & hosenterest. & 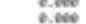 & ${ }_{1.000}^{0.000}$ & 0.000 & 8.900 \\
\hline & Mutumbonthets & $=\infty$ & $x$ & $\therefore$ & 10.58 \\
\hline
\end{tabular}

Fig. 1. Centrality Degree per stakeholder 
The centralization indicator visually displays which are the more centralized stakeholders in the activity due to the number of links they have in relation to other stakeholders. On this basis, it can be appreciated that for the activity most public institutions and all social organizations are located in the center of the graph, which can mean that they have a more relevant role than other stakeholders. This could help consolidate the links and they could be strategic stakeholders for improvement of the activity's regulatory framework, giving way to a sustainable development of the resource and taking into account the productive progress and the need of stakeholders. Visually, PRODUCE, COPMAR, IMARPE Marcona and DIREPRO Ica are the organizations that tend to have higher centralization degree not only because they are in the center of the graph but because they present greater number of links with other stakeholders.

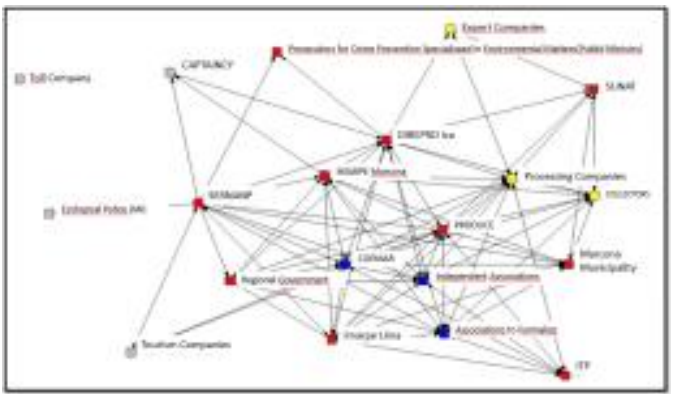

Fig. 2. Stakeholders linkage by Institution type (Centralization Graph)

The intermediation indicator is expressed by the geodesic distance which refers to how many minimum and maximum steps each stakeholder takes to reach or be linked to another. This helps to know how many bridges or intermediaries (intermediation level) must be crossed to reach contact with other stakeholders. If they are minimum steps, it may help each stakeholder to generate rapid action to achieve an agreement. However, if there are maximum steps, these can hinder communication with the required stakeholder when facing a situation.

To read the table of geodesic distances minimum steps, it is necessary to consider that value 0 expresses relation with itself; the values from 1 to 4 is the number of intermediaries that have to be crossed to communicate with each other; and the empty spaces show linkage inexistance between one stakeholder and another.

Fig. 3. Geodesic Distance Minimum Steps

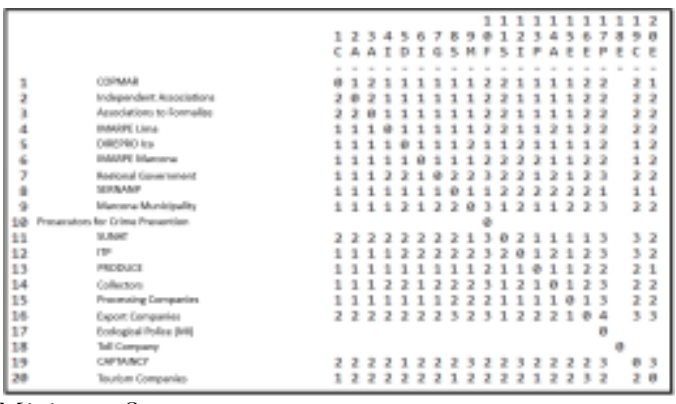

(C) 2018 The Authors. Journal Compilation 들 2018 European Center of Sustainable Development. 
To read the table of geodesic distances maximum steps, the codification of links is as follows: value 0 is the absence of intermediation and values from 1 to 17 are the maximum number of intermediaries that a stakeholder has to cross to reach another.

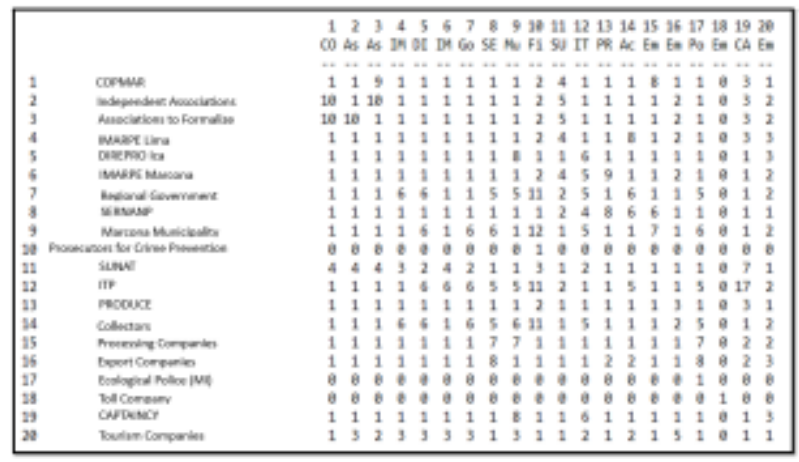

Fig. 4. Geodesic Distance Maximum Steps

The obtained results give way to the following analysis:

At the beginning PRODUCE stakeholder stated that its participation level within the activity was not high, but the previously obtained results show that due to its role, it is in a relevant position. Besides, in the minimum steps chart it is the stakeholder that has the least number of bridge steps and, in the maximum steps chart, it only has to cross a maximum of three steps to communicate with another stakeholder. This shows that it not only has closeness to other stakeholders or that it has authority - interest within the chain, but it also has an efficient number of intermediaries to reach other stakeholders and generate adequate coordination processes. On the other hand, the initial perception of IMARPE Marcona was that it had great importance within the activity, but its position in closeness and in authority-interest is not so. In the analysis of minimum steps this stakeholder requires two intermediaries, but in maximum steps requires nine. This generates concern because it will depend on what it wants to convey and the context to summon stakeholders and more so to establish strategic relationships. This indicator helps to contrast stakeholder perceptions and evidences the existing complexity in its links.

Closeness and density indicators must be worked first for the entire network where it was found to present a density of $37.89 \%$ of the possible links, as for each stakeholder to understand the relationship of each node with the others. Therefore, closeness reveals information that makes possible to adequately control conflicts because it is possible to identify which relationships or links are missing to generate an integration that enables the generation of new links and sustainable agreements over time. On the other hand, density shows the total number of existing links in a group of stakeholders divided by the maximum total number of relationships that can be generated. This enables examination of the real relationships each stakeholder has, generating a comparative analysis with the total number of links that it could have. At this point, one stakeholder, PRODUCE, will be taken as reference to show the contribution of the indicators.

This stakeholder is in a central position in relation to other stakeholders. The graph shows that it has closeness with 14 stakeholders but does not have any link with other 
five. Its density level is $68.42 \%$, which means that of the 38 possible input and output links it can have, at present it is using 26 links, showing that it not only has interest and authority within the activity but that it is exerting its communication capacity and its relationship with other stakeholders. However, it is a public organization; as such it should generate linkage with the other five stakeholders with the aim to achieve better relationship and improved performance within the activity context.

Fig. 5. Closeness Linkage by Institution Type - PRODUCE
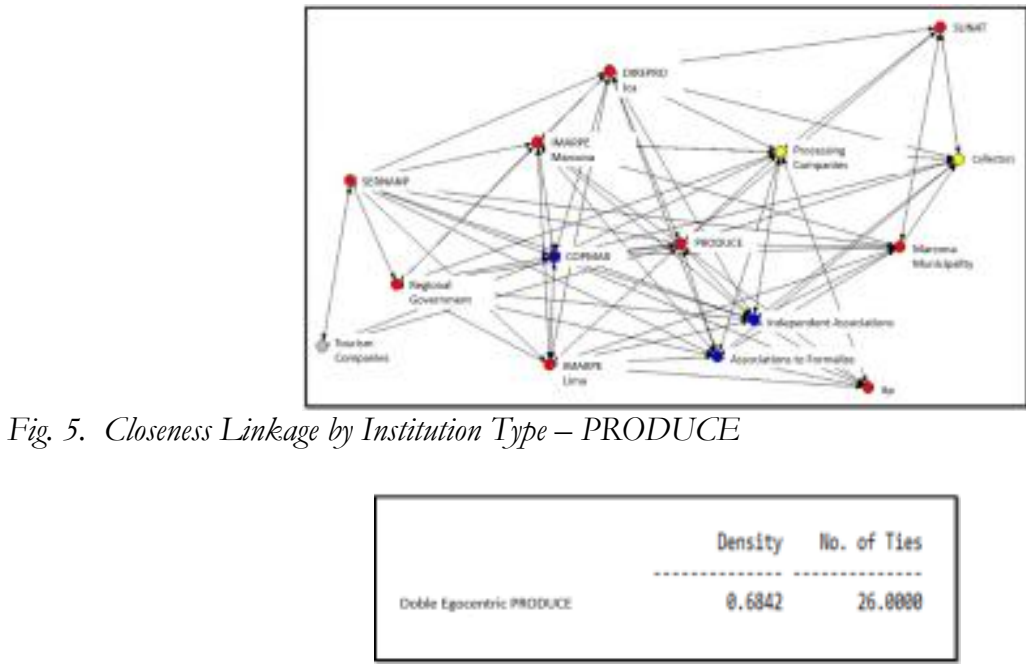

Fig. 6. Average Density per stakeholder - PRODUCE

The UCINET program explains stakeholder by stakeholder the closeness they have with each other and shows the relationships that have been achieved. It also points out the stakeholders that are still free of relationships. They should work to be active stakeholders in the network because each one has a relevant purpose in the development of the activity in the area. Besides, density gives the number of input and output links of each stakeholder as compared to the links it could have. This makes possible to think about the links they actually have and those they should build and strengthen.

\section{Conclusions}

To understand management requirements of stakeholders in strengthening governance of sustainable development of Peruvian marine resources, this research used a study case. Snowball sampling by saturation was used to identify direct and indirect stakeholders involved in the collection and commercialization process of brown macroalgae in Marcona district. On the other hand, to propose governance guidelines, it was necessary to analyze the intensity of the relationships that stakeholders maintain within the analyzed productive chain. Therefore, systematization of the qualitative findings enabled, with the elaboration and analysis of the networks, to determine the linkage levels that existed between the 20 identified stakeholders involved in the sustainability of brown macroalgae activity.

This way, information gathering, interviews and surveys carried out by different 
stakeholders could be systematized and reflected in sociograms that facilitated the quantification of density, centrality, closeness, centralization and intermediation degrees. Therefore, the use of the UCINET program gave very enriching results to obtain the conclusions of the research in regard to the relationship of stakeholders according to the roles they handle, the existing links and the rapprochements that should be given for strengthening governability that determines sustainable development of the activity. The network analysis that has been generated as part of the research has enabled visualization of the density of the entire network which is $37.89 \%$, based on the interrelationship among stakeholders. In particular the analysis of the links of public stakeholders who are responsible for the sustainable development perspective has been prioritized as they determine the route to adequate management of brown macroalgae collection and commercialization. Besides, they are in charge of giving the regulations that frame the activity, enabling a sustainable use of the resource and generating good relations that seek to minimize conflicts.

These analyses show the complexity of the relationships and the linkages between stakeholders, how this is reflected in governance and how it enables sustainability of the activity. Concern for sustainability of the resource prevents its depredation and the irreversible effect on biodiversity. The interviewed stakeholders agree that its preservation is one of the core pillars because without a correct use of macroalgae and an adequate normative framework, the activity would finally impact negatively in the marine ecosystems and in turn, in the economic and social development of the area.

\section{References}

Aguirre, J. L. (2011). Introducción al Análisis de Redes Sociales. Bueno Aires: Centro Interdisciplinario para el Estudio de Políticas Públicas.

Andia Valencia, W., \& Andia Chavez, J. (2009). Manual de Gestion Ambiental. Lima: Centro de investigacion y capacitacion empresarial.

Direccion General de Promocion Agraria. (17 de Junio de 2013). Ministerio de Agricultura. Obtenido de www.minag.gob.pe

Fairlie Reinoso, A. (2010). Biocomercio en el Peru: Experiencias y propuestas. Lima: Pontificia Universidad Catolica del Peru.

Instituto del Mar Peruano - IMARPE. (2009). Estudio de investigacion de poblaciones y de las condiciones de viabilidad ecologica de las actividades extractivas de algas pardas e invertebrados en la zona costera sur, en apoyo a la investigacion y desarrollo del IMARPE. Lima: ICON - INSTITUT.

Malajovich, M. A. (2005). Biotecnologia. Buenos Aires: ArgenBio.

OECD. (23 de Febrero de 2018). OECD: Mejores Políticas para una Mejor Vida. Obtenido de https://www.oecd.org/greengrowth/49709364.pdf

PERCAN. (2011). Manual de Gestion Social. Lima: Ministerio de Energia y Minas.

Revesz, B. (2009). Gobernanza, procesos participativos y desarrollo territorial. En H. Mazurek, Gobernabilidad y gobernanza de los territorios de America Latina (pág. 33). Lima, Peru: Instituto Frances de Estudios Andinos, UMIFRE 17.

The Regency corporation Limited in Asociation with the United Nations. (1998). Sustainable Business: Economic Development and Environmentally Sound Technologies. Malawi: The Regency Corporation Limited.

Ugalde Gómez, J. A., Herrera Villalobos, A., Obando Acuña, V., Chacón Chavarría, O., Vargas Del Valle, M., Matamoros Delgado, A., \& García Víquez, R. (2009). Biodiversidad y Cambio Climático en Costa Rica. Costa Rica: Instituto Nacional de Biodiversidad.

Velázquez Alvarez, A., \& Aguilar Gallegos, N. (2005). Manual Introductorio al Analisis de Redes Sociales. México: Universidad Autónoma del Estado de México. 